\title{
INTERNAL AND EXTERNAL RISK BASED ASSESMENT AND EVALUATION FOR THE LARGE INFRASTRUCTURE PROJECTS
}

\author{
Ivana BURCAR DUNOVIC, Mladen RADUJKOVIC, Mladen VUKOMANOVIC \\ Department of Construction Management, University of Zagreb, Kaciceva 26, HR-10000 Zagreb, Croatia
}

Received 10 Mar 2015; accepted 01 Nov 2015

\begin{abstract}
The level of sensitivity to project success of large infrastructure projects is significantly greater in front-phase than in execution phase. Yet, due to focus on execution phase, methods for project assessment and on-going evaluation during front phases are insufficiently developed. On the other hand, risk management approaches has been moved from risk management towards holistic uncertainty management which is the most beneficial in front end phase of the project. This research identifies that majority of methods and techniques available does not support uncertainty management concept. The purpose of this paper is to develop and new method for risk based project assessment and evaluation integrating risk impact modelling using cumulative distribution curves (CDC) and multi-criteria project evaluation approach. Research is based on in-depth risk analysis of 15 large infrastructure projects using risk model of components and characteristics. The conclusion of the paper is verification and validation of method that combines qualitative and quantitative analysis using risk components, risk breakdown structure, AHP method and risk impact modelling using cumulative distribution curves (CDC) for internal and external risk based assessment and evaluation of large infrastructure projects.
\end{abstract}

Keywords: front end phases, internal and external, project assessment and evaluation, large infrastructure projects, AHP, cumulative distribution curves, risk model, risk components.

\section{Introduction}

As a result of very frequently undershooting the expected results, and due to their great visibility and impact, large projects have gained a bad reputation. This bad reputation has prompted a series of research projects that focus on two features - long duration and high exposure to risk, which are key for large projects. The IMEC project results (Miller, Hobbs 2005; Miller, Lessard 2000) and Flyvbjerg and Bank (2005) point strongly to the problem of lengthy duration, especially at the beginning of a project when the project is highly susceptible to various external and internal influences. The development of a project during the preliminary phases is a time-dependent, non-linear and iterative process during which the project is formulated, tested, tried out and reformulated through a series of episodes (Miller, Hobbs 2005). Unpredictable risks and problems arise in successive episodes that must be managed. Methods which have been developed to date for the continuous monitoring and evaluation of the progress of a project for the execution phase rely on the measurement of progress of the project with the aid of specific concrete units of measurement, such as money, time and physical units or they are focussed to the evaluating and monitoring the key performance indicators (Radujković et al. 2010). The research of large projects cleared the critical importance of "front-end" phases, where risks and uncertainty have the greatest value (Dunovic 2010; Miller, Lessard 2000; Samset, Volden 2014). Progress evaluation of project in front-end phases cannot be based on time or money spent and available progress methods become inapplicable due to the lack of an efficient way to measure project state. It is therefore necessary to develop an efficient method for evaluation and measuring the progress of a project that is applicable in the initial, preliminary phases of projects that have a very important role in the success of large projects. Uncertainty and risks have "mirror" of the external and internal influences on a project because uncertainty affects the final outcome of a project and comes from internal and external circumstances and changes. This paper aims to develop and validate a method for external and internal project assessment and evaluation through lens of risks using uncertainty management approach. Method will be used to evaluate the status of large projects that will be based on the monitoring and evaluation of the uncertainty in a project through whole lifecycle of the project.

\section{Literature review}

Historical review (Taroun 2014) showed general focus of risk management to development of risk analysis 
and assessment. To support multi-criteria decision making, various multi-criteria analysis methods are used for risk assessment (Ceric, Marić 2011; Zavadskas et al. 2010), fuzzy analysis and recently, fuzzy cognitive maps (FCM), extended fuzzy cognitive maps (E-FCM) (Lazzerini, Mkrtchyan 2011) and analytical network process (ANP) (Bu-Qammaz et al. 2009; Lu et al. 2007), mostly with purpose to derive the relative priorities of risk factors and only to cost and duration as main criteria, while other criteria are ignored. Very few authors researched in field of risk monitoring and communication. Kim (2010) developed risk performance method, while few authors developed risk knowledge-based management systems (Burcar Dunović et al. 2013; Patterson, Neailey 2002; Tah, Carr 2001). Although highly criticized (Cagno et al. 2007; Charette 1989; Dikmen et al. 2007; Jannadi, Almishari 2003; Williams 1996; Zhang 2007), the most common form of risk modelling uses a size that represents the intensity of risk given the likelihood of occurrence and size of the impact, the so-called P-I model. Although each of the proposed improvements is justified, Taroun et al. (2011) consider that the mathematical model of construction risk has to be expanded to cover additional explicit parameters besides probability and impact.

Entering in the 21st century the idea that risk management is not enough started to evolve (Jaafari 2001; Pender 2001), when uncertainty management started to evolve. Not many authors other than Chapman and Ward worked on operationalization of the concept of uncertainty management (Chapman 2006; Chapman, Ward 2003). Techniques for uncertainty management are not yet developed enough to be used widely in practice. Literature and project management methodologies consider risk management as one part of project management. But, to be fully effective it has to be closely integrated in to overall project management process (Hillson, Simon 2007), providing data for decision-making process through whole lifecycle of the project. Much of good project management practice can be thought of as effective uncertainty management (good practice in planning, coordination, setting milestones, and change control procedures seek to manage uncertainty directly) (Chapman, Ward 2003).

In place of the P-I approach, Chapman and Ward offer a completely different approach - cumulative curves (Chapman 2006), which also enable modelling of the correlation of the impact of risk assuming a perfect positive correlation. In this way, cumulative curves can be used to sum up the impact of risk (Chapman 2006; Chapman, Ward 2003). As Figure 1 shows, when subjective estimate is used for risk estimation, P-I approach does not represent important information - the uncertainty of estimation, as one of important sources of uncertainty. Even a simplified form in the form of a line is considered a much better approach than the P-I matrix. P-I approach and cumulative curves are two different approaches and cannot be combined; it is necessary to develop new methods for project risk assessment using CDC approach (Chapman, Ward 2003).

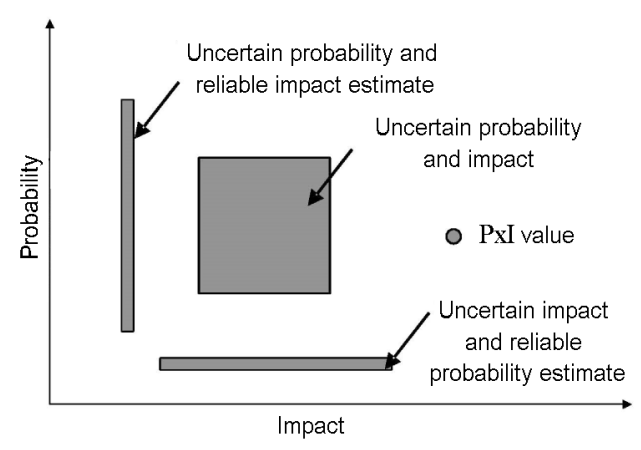

Fig. 1. Comparison of "minimalist" view (adapted from Chapman 2006) with P-I approach

The literature review shows that development in risk management is focused in risk assessment and modelling area and is rather detached from the longitudinal aspect of project development and decision-making. Longitudinal aspect of large project risk management in this paper is researched from aspect of project assessment and evaluation for two reasons: it is evidence on integration of risk management and decision-making, and it is important part of governance frameworks for large projects. Although, majority of risk management methodologies (ATOM, MoR, PMBoK, PRAM, RAMP) include risk monitoring very few authors researched in field of risk monitoring and communication (Burcar Dunović et al. 2013; Patterson, Neailey 2002; Tah, Carr 2001) and is no research done on progress monitoring, assessment and evaluation during the front end of project. It is important to understand and to manage overall project uncertainty and what is its root cause. Risk sources and drivers are what project management should be focused on. This is why we are proposing to assess project based on risks and uncertainty, focusing on sources and drivers taking into account all project success criteria. This is why we are using previously mentioned approach to uncertainty management (Chapman, Ward 2003), which will integrate knowns, known unknowns and unknown unknowns in one method. Report on risks in front end of megaprojects resulted with three parts of uncertainty management, which needs to integrate three types of uncertainty looking from epistemological aspect - variability, risks and lack of knowledge, which provides the context to this research (Alfalla-Luque et al. 2015).

\section{Research methodology}

Looking from epistemological aspect, due to the complexity of the mechanism of activity of risk in a project, the assessment cannot be formed only on the basis of sources of risk. All the components of the previously developed model need to be taken into consideration (Fig. 2). It was therefore necessary to devise a procedure for quantifying the components of risk, based on the impact on project results. Cumulative distribution curves are often generated on the basis of a subjective estimate due 


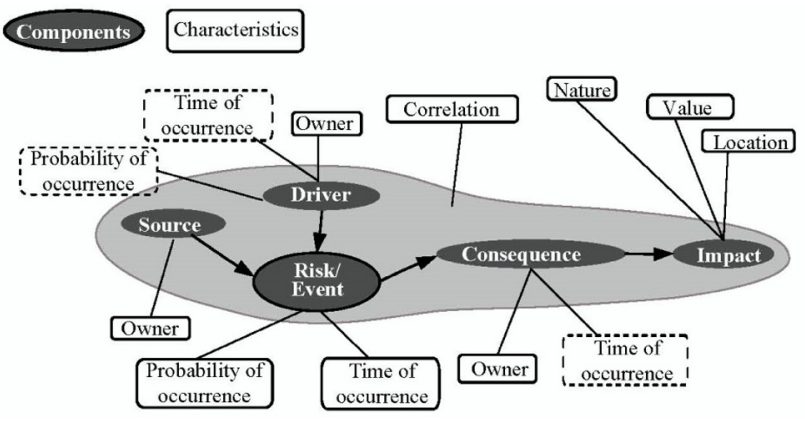

Fig. 2. Components and characteristics of risk (Burcar, Radujković 2009)

to the lack of historical data on large projects and it is essential to carry out such an analysis for all of the criteria of project success.

Based on review and analysis of the literature, the authors have concluded that for integrated analysis of overall uncertainty is more applicable for large complex projects to use cumulative distribution curve modelling, as it was suggested by Chapman (2006), then other methods due to large amount of ambiguity, especially in front end phase. There are two problems that needed to be solved: integration cumulative distribution (CDC) with multi-criteria approach and using sources and drivers to evaluate project in front-end phase. Therefore, the aim of this research is to answer research question: Саn ситиlative distribution $(C D C)$ approach be used to develop a new method for project risk-based assessment and evaluation considering project multi-criteria and complexity of causes that generate project uncertainty?

The research was performed in four major parts: the literature review, data analysis, method development and verification and conclusion (Fig. 3).

Risk Breakdown Structure is a tool that has long been used for the identification, structuring and categorization of risk. This research is based on the Source Risk Breakdown structure that divides sources into external and internal (Burcar Dunović et al. 2013; Radujković, Burcar 2005), which makes it suitable for internal and external assessment of a project. However, original structure is the result of research on only the source of risk, which is why this research that covers the other components of risk has been conducted. For this purpose we are particularly interested in drivers, since they, together with sources, trigger the risk mechanism, and are, therefore, along with sources, key to project assessment. In order to form a final internal and external assessment, research of the components and characteristics of risk was carried out. Through in-depth analysis of 15 large infrastructure construction projects, the identification and categorization of risk components that influenced the project results was performed. Monte Carlo simulation is used to confirm mathematical approach to building equations for integration of CDC and AHP, as well as for risk components quantifications. Verification is carried out through the application of the method on large infrastructure project to demonstrate how the method is applied and used. For the verification of the method simulations are used based on data collected from the design and execution phases of projects, which are used for front-end phase simulations. To validate the method is used expert opinion to assess importance, applicability, and clarity of the method as well as to identify which problems are addressed with this method and at what extent, using Likert scale from 1-5.

\section{Developing the risk-based assessment and evaluation method}

In addition to influencing the outcome of a project, risks are "mirror" of external and internal influences on a project, because uncertainty affects the final outcome of the project, and comes from internal and external circumstances and changes. Research on a sample of drivers has shown that drivers can be categorized in the same classification as sources, which resulted in a breakdown structure of sources and drivers of risk. The RBS structure at the first and second level is equal to the RBS sources, while there is a difference only at the third level.

At the beginning of the assessment qualitative risk analysis is performed on the basis of previously developed risk model. Through the process of risk iden-

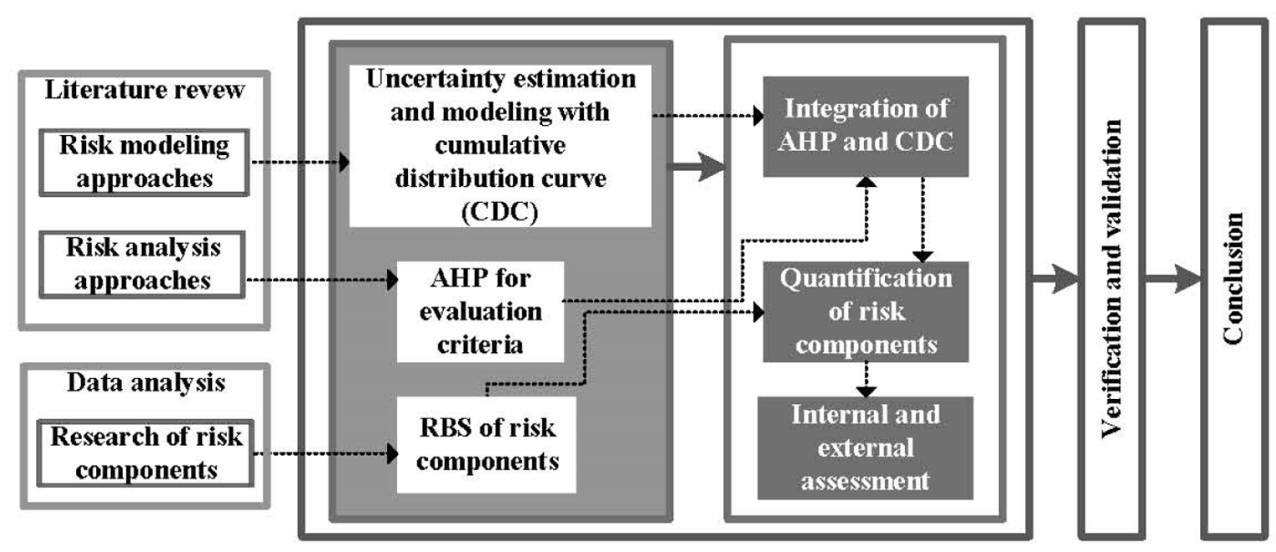

Fig. 3. Research methodology 
tification, elements of a qualitative risk model, i.e. risk components, are identified. Qualitative analysis includes determining their interconnectivity and defining which type of components they belong. It is very important that the process begins with recognition of the consequences that should be directly related to the results of the project and success criteria, in order to avoid the mistake of immediately determining the impact. The consequence is used to identify the elements that are needed for quantitative modelling. For each result it is necessary to connect the risk event, which represents a risk in the model for quantitative analysis, while the impact determines in which model it will be included, depending on which indicator influences. For each risk event the driver(s) and source are identified.

The previous analysis shows that modelling through cumulative probability distribution curves is the most appropriate way of modelling all types of uncertainty. Therefore, for the value of consequences and risks instead of the P-I model the cumulative curve model is used. The ultimate impact of a risk will be expressed in a cumulative curve in a monetary variable. To assess the impact of a risk, a percentage of the net present value (NPV) is used. The NPV was chosen because it is the most widespread economic method of establishing the criteria for the acceptance of a project, particularly for infrastructure projects. One can argue that all loss cannot be valued with NPV but even loss of human life can be valuated using different methods of valuing human life (Dorman 2009; Max et al. 2004).

The criteria for project assessment cover a much broader range than cost and time. In order to enable a comprehensive assessment of a project, the first step is to determine the criteria and system of measurement based on which the project will be assessed. To reduce the complexity of the problem it is necessary to ensure the independence of the criteria. In this case, it is possible to use AHP to determine the importance of each criterion.

The person who decides and who is capable of prioritizing the importance of factors within the AHP method should be able to estimate the impact arising from a risk. Furthermore, practitioners who are able to determine the size and cost of the remaining risks, unknown unknowns and to assess contingencies will be able to make known the size and cost of the known unknown (Taroun et al. 2011).

The fact that the sources and drivers of risks in large construction projects can be classified according to an initial RBS enables to use RBS for internal and external assessment of a project and to create a framework for modelling the impact of uncertainty on a project. This framework enables a Project Results Assessment (PRA), Project Internal and External Assessment (PIEA) (Fig. 4).

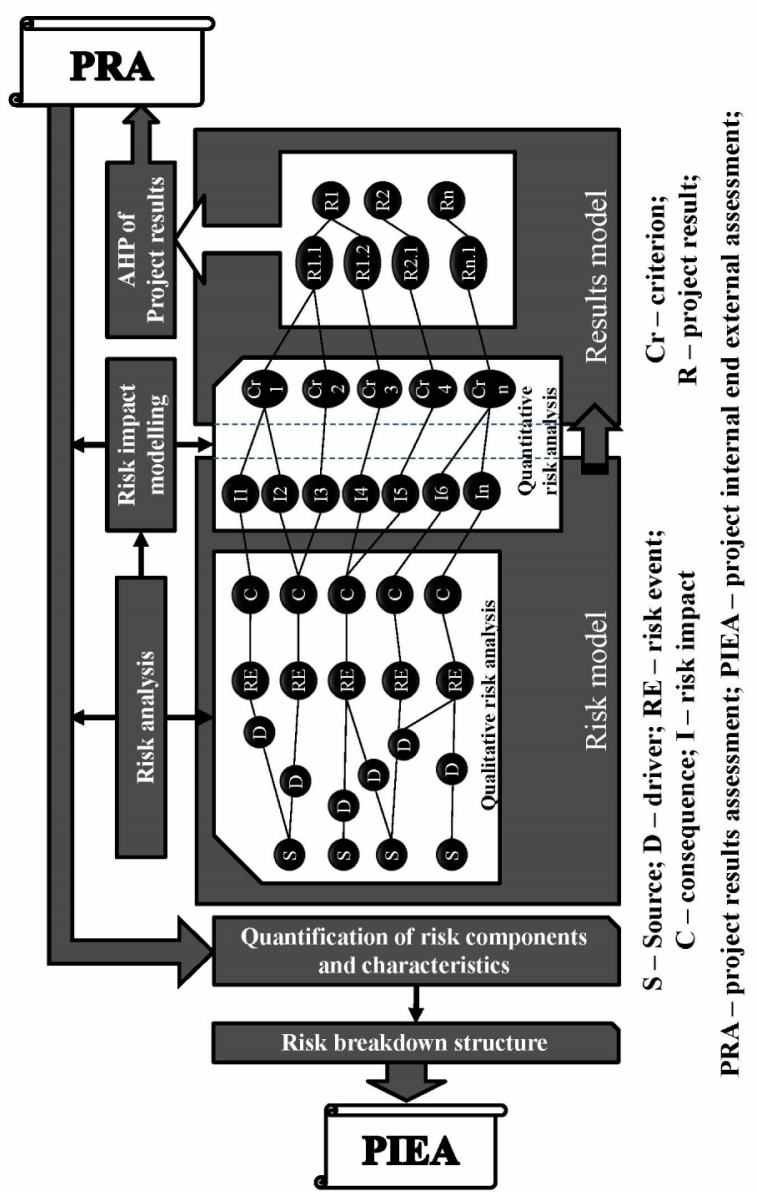

Fig. 4. Illustration of project assessment method

\subsection{Integration of multi-criteria analysis and the method of summation of cumulative probability distribution}

The central problem of this method is integration of project results and risk components using cumulative distribution curves (CDC). Looking from risk management point of view the curves are representing the impact of risks on the project objectives and therefore on results. Impact of risks can be presented using probability distribution (uniform, triangle, normal, beta, PERT, etc.) or using cumulative distribution (line or s-curve). Each distribution function has corresponding cumulative distribution function. In this research we used the ideal case of the cumulative curve - the line, instead of s-curve, which is good risk portrait showing both, expected value and uncertainty of risk estimation (Chapman, Ward 2004). It has two values that determine it - the expected value and the steepness of the line. The expected value $E V$ is the value of the impact of a risk that has a $50 \%$ probability of occurrence, while uncertainty is represented with slope of the line (in work of Chapman and Ward (2004) it is called risk portrait). Mathematically, slope of the line is $\tan a$, but for this purpose the slope of the line as measure of uncertainty will be $\tan b$ which is equal to $M(\max )-$ $m(\mathrm{~min})$, since total range of probability is between 0 and 1 . 


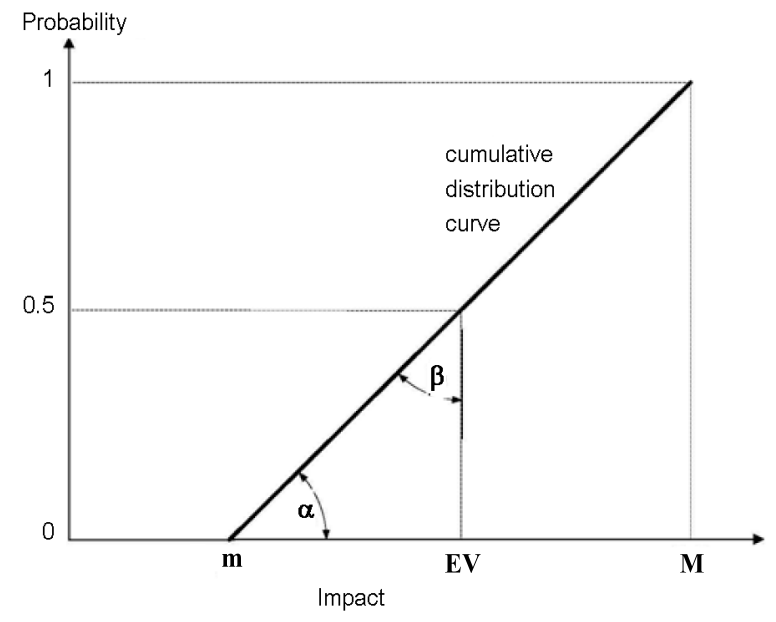

Fig. 5. Illustration of risk and uncertainty measures on ideal case of cumulative distribution curve (adopted from Chapman 2006)

It is important that project results are structured and for each lowest level of results, i.e. a criterion for assessment, one cumulative curve is obtained for each criterion as a value and that they are expressed in the same unit (discounted net present value). Since project objectives have hierarchical structure it is necessary to apply partial AHP procedure in order to set value of the importance of project objectives and results.

To develop proposed method, it is necessary to determine which characteristics of the cumulative curve will be used and in which way for indicators of project status. Then, it is necessary to perform two types of calculations using selected indicators, multiplication of the cumulative curve with a constant number, and summing up two cumulative curves. For the overall impact on the results, two sizes will be used: the sum of weighted expected value (EV) of the results on the lowest level and sum of two weighted uncertainty measures - the slope $S=\tan b=M-m$ and ratio between $S$ and $E V$ which we will call efficiency of risk ER (Fig. 5).

Considering previously defined variables, if we multiply the line with constant $n$ we will multiply both $E V$ and $S$, which will result in the $E V$ being $n$ times larger, and the $E R$ will remain unchanged (Fig. 6). This indicates that efficiency of risk is not dependent on weighted factors, which makes one more advantage of its use as a measure of total uncertainty. This is important information for future interpretation of the data.

The procedure of adding and subtraction of cumulative curves is shown in Figure 7. In this case, the expected value can be added and subtracted, while the overall efficiency of risk $(E R)$ will not be obtained through summing up the efficiency of risk of individual variables $(e r)$, but by summing up the efficiency of risk value in relation to the total expected value. This value will show how much each risk contributes total uncertainty and will be called "related efficiency of risk" (rer). When calculating the sum of "related efficiency of risk" (rer) it will result

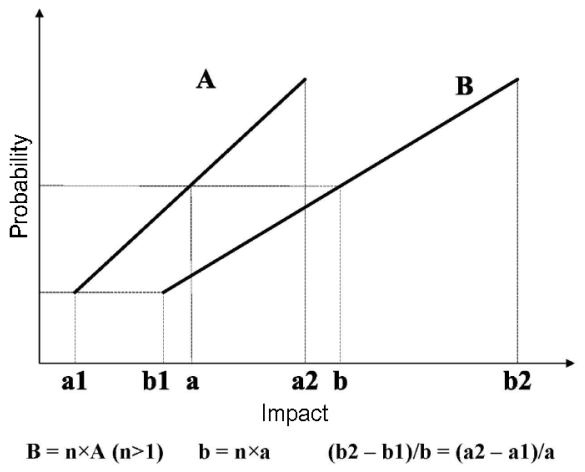

Fig. 6. Multiplication of cumulative curve by coefficient

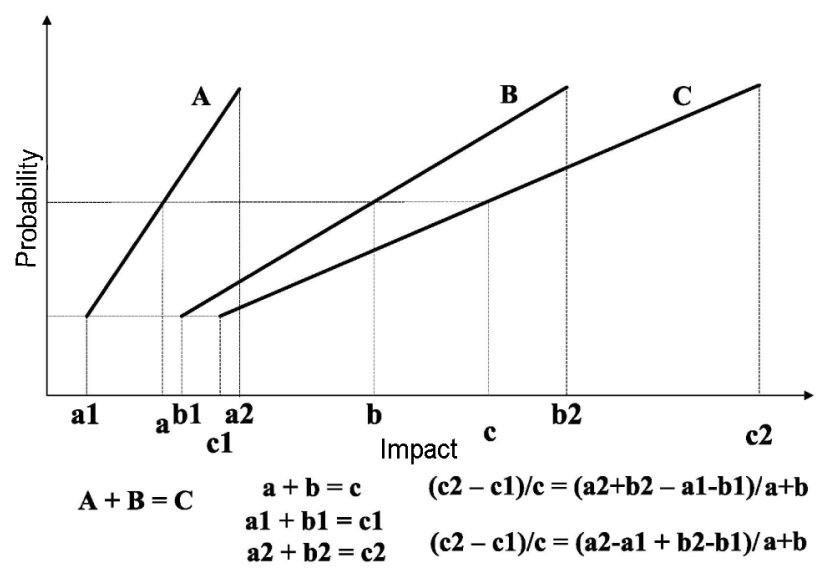

Fig. 7. Summing up of two cumulative curves

with "total efficiency of risk" $(E R)$, which will depend on weighted factors. The calculations used in the cumulative curves method were checked with the aid of Monte Carlo simulation. Results and comparison showed difference not greater than $6 \%$ which is acceptable.

For the calculation of individual and total expected value and efficiency of risk for impact on each success criteria the following formulas are used:

$$
\begin{aligned}
& e v_{r}=\sum_{i} e v_{r i} ; \\
& s_{r}=\sum_{i} M_{r i}-m_{r i}=\sum_{i} s_{r i}=M_{r}-m_{r} ; \\
& e r_{r i}=\frac{M_{r i}-m_{r i}}{e v_{r i}}=\frac{S_{r i}}{e v_{r i}} ; \\
& r e r_{r i}=\frac{M_{r i}-m_{r i}}{e v_{r}}=\frac{S_{r i}}{e v_{r}} ; \\
& e r_{r}=\frac{\sum_{i} \boldsymbol{M}_{r i}-\boldsymbol{m}_{r i}}{e v_{r}}=\frac{\sum_{i} s_{i}}{e v_{r}}=\sum_{i} \boldsymbol{r e r}_{r i} .
\end{aligned}
$$

The integration of CDC and AHP includes calculating weighted values for each success criteria $r, E V_{w}$, $S_{w}$ and $E R_{w}$, the calculation procedure and formulas of 
which is shown below. Indicators for the part of the assessment related to project results will be obtained with this procedure:

$$
\begin{aligned}
& e v_{w r}=e v_{r} * w_{r} \\
& s_{w r}=\left(M_{r}-m_{r}\right) * w_{r}=s_{r} * w_{r} ; \\
& e r_{w r}=\frac{\left(M_{r}-m_{r}\right)^{*} w_{r}}{e v_{r} * w_{r}}=\frac{\left(M_{r}-m_{r}\right)}{e v_{r}}=\frac{S_{r}}{e v_{r}}=e r_{r} \\
& E V_{w}=\sum_{r} e v_{r} * w_{r}=\sum_{r} e v_{w r} ; \\
& S_{w}=\sum_{r}\left(M_{r}-m_{r}\right) * w_{r}=\sum_{r} s_{r} * w_{r}=\sum_{r} \boldsymbol{s}_{w r} \\
& r e r_{w r}=\frac{\left(M_{r}-m_{r}\right) * w_{r}}{E V_{w}}=\frac{s_{w r}}{E V_{w}} ; \\
& E R_{w}=\frac{\sum_{r}\left(M_{r}-m_{r}\right) * w_{r}}{\sum_{n} e v_{i}^{*} w_{r}}=\frac{\sum_{r} s_{w r}}{E V_{w r}}=\sum_{i} r e r_{w r}
\end{aligned}
$$

In the overall assessment the expected value $\left(E V_{w}\right)$ will be used as an overall indicator of changes relating to the expected results, while slope $\left(S_{w}\right)$ and the total efficiency of risk $\left(E R_{w}\right)$ will show the measure of uncertainty of the results. If this is shown in the form of a simple cumulative curve we will see that changes in the expected value of the results will be interpreted through translation in horizontal direction, while changes in the uncertainty of the results will be interpreted through the change of slope (Fig. 8).

The weighted values can be used for comparison purposes, but they will not reflect real value. In order to represent the "real" value of risk impact, weighted values of expected value $e v_{w r}$ and $E R_{w}$ and slope $S_{w r}$ and $S_{w}$ have to be normalized with coefficient $n=\frac{\sum_{r} \boldsymbol{e} \boldsymbol{v}_{\boldsymbol{r}}}{\boldsymbol{E R}_{\boldsymbol{w}}}=\frac{\boldsymbol{E} \boldsymbol{R}}{\boldsymbol{E} \boldsymbol{R}_{w}}$. This normalization will not affect

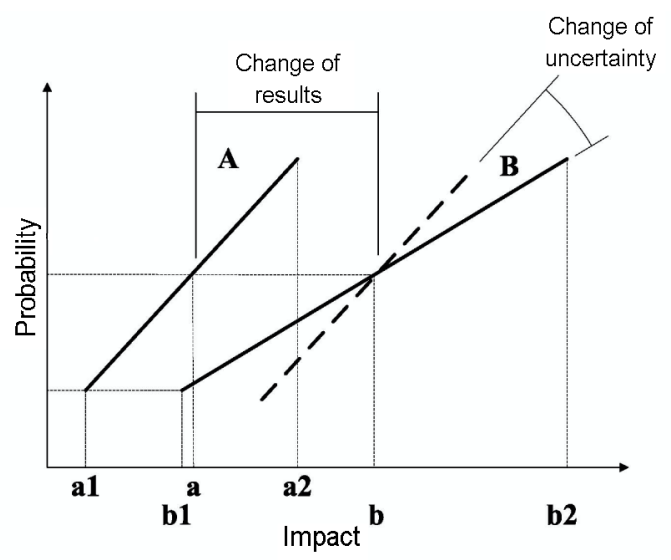

Fig. 8. Interpretation of results values $e r_{w r}, r e r_{w r}$ and $E R_{w}$. This mathematical procedure present how quantitative assessment of a project with respect to project results, combination of three indicators of cumulative probability distribution variables can be used to monitor risks in a project - expected value, with which the impact of risk on the size of the results is measured and slope and risk efficiency, with which the impact of risk on the uncertainty of the results is measured.

\subsection{Quantification of risk components}

Results from the data collected through risk analysis on the projects included in this research, allow the application of RBS for internal and external assessment of a project based on sources and drivers of risk. However, it is necessary to first carry out quantification of the components of risk. For the quantification of risk components, the results of the impact of individual risks on the overall results of the project will be used. Now to each component of risk can be assigned a value with regard to how the risk event to which it belongs affects the overall results of the project.

Therefore, for the quantification of individual RBS categories, the calculated size of expected value and efficiency of risk will be used. The value of each risk will depend on the number of impacts it has, i.e. on how many criteria are impacted, on the value of its impact, and on the weight of each criterion.

For each risk $i(i=1,2,3, \ldots, n)$ it is possible to calculate the total expected value of the impact and the related efficiency of risk given the importance of the result i.e. weight of the impact $e v_{w i}, s_{w i}$ and $e r_{w i}$, with the formulas:

$$
\begin{aligned}
& e v_{w r i}=e v_{r i} * w_{r} \\
& s_{w r i}=s_{r i} * w_{r} ; \\
& s_{w i}=\sum_{r}\left(M_{r i}-m_{r i}\right) * w_{r}=\sum_{r} s_{r i} * w_{r} ; \\
& e r_{w r i}=\frac{\left(M_{r i}-m_{r i}\right)^{*} w_{r}}{e v_{r i} * w_{r}}=\frac{\left(M_{r i}-m_{r i}\right)}{e v_{r i}}=\frac{S_{r i}}{e v_{r i}}=e r_{r i} \\
& e v_{w i}=\sum_{r} e v_{w r i}=\sum_{r} e v_{r i} * w_{r} ; \\
& r e r_{w r i}=\frac{\left(M_{r i}-m_{r i}\right) * w_{r}}{e v_{w i}}=\frac{s_{w r i}}{e v_{w i}} \\
& e r_{w i}=\frac{\sum_{r}\left(M_{r i}-m_{r i}\right)^{*} w_{r}}{\sum_{r} e v_{r i} * w_{r}}=\frac{\sum_{r} s_{w r}}{e v_{w i}}=\sum_{r} r e r_{w r i}
\end{aligned}
$$

where $r=1,2, \ldots, k$ is the number of success criteria that are affected by the risk event, for which $k$ is the total number of criteria. 
In order to avoid the perception of increase of the expected values of management from the results, each component will bring one portion of the expected value in the internal and external assessment of a project. For this reason, the expected value attributable to the risk will be divided into an equal number of parts depending on the number of components. Since the size of the efficiency of risk cannot be directly added and subtracted, for calculation of the efficiency of risk, an appropriate proportion of slope will be used, i.e. max-min intervals, and efficiency of risk for an individual RBS category will be calculated in relation to the total estimated value that belongs to it. As a result, individual RBS categories are valuated using values that describe the level of risk, the expected value, slope and the efficiency of risk.

For each risk component the values can be determined based on assumption that every component (sources and drivers) have the same importance for triggering the risk mechanism:

$$
\begin{gathered}
e v_{i c}=\frac{e v_{w i}}{c} ; \\
s_{i c}=\frac{s_{w i}}{c} ; \\
e r_{i c}=\frac{e r_{w i}}{c},
\end{gathered}
$$

where $c$ is number of risk components associated with corresponding risk event. Each of the risk components is associated with one category of RBS and values of one category summarize all values of components categorized within the same category:

$$
\begin{gathered}
e v_{C A T j}=\sum_{i c} e v_{i c j} ; \\
s_{C A T j}=\sum_{i c} s_{i c j} ; \\
e r_{i c j}=\frac{\boldsymbol{S}_{i c j}}{\boldsymbol{e} \boldsymbol{v}_{i c j}} ; \\
r e r_{i c j}=\frac{S_{i c j}}{E V_{w}} \\
\boldsymbol{e r}_{\boldsymbol{C A T j}}=\frac{\sum_{\boldsymbol{i}} \boldsymbol{M}_{\boldsymbol{r i}}-\boldsymbol{m}_{\boldsymbol{r i}}}{E V_{w}}=\frac{\sum_{j} \boldsymbol{s}_{i c j}}{E V_{w}}=\sum_{\boldsymbol{i}} \boldsymbol{r e r} \boldsymbol{i}_{i c j} .
\end{gathered}
$$

Values at the first RBS level will be obtained using the same formulas by summing up the values of the category that belong to an internal or external category.

In this way separate project assessments can be obtained, internal assessment of the project and external assessment of the project, as well as their combined value:

$$
E V_{(\text {Iand } / \text { orEPA })}=\sum_{j} e v_{C A T j}
$$

$$
\begin{gathered}
\boldsymbol{S}_{(\text {Iand/orEPA })}=\sum_{j} \boldsymbol{s}_{\boldsymbol{C} A T j} ; \\
e r_{C A T j}=\frac{S_{C A T j}}{e v_{C A T}} ; \\
\operatorname{rer}_{C A T j}=\frac{S_{C A T j}}{E V_{w}} ; \\
\boldsymbol{E R}_{(\text {Iand/orEPA })}=\frac{\sum_{j} \boldsymbol{S}_{C A T j}}{\boldsymbol{E} \boldsymbol{V}_{\boldsymbol{w}}}=\sum_{i} \boldsymbol{r e r}_{\boldsymbol{C A T j}} .
\end{gathered}
$$

Note that in last two steps, when calculating rer and er for each level of RBS, i.e. category and internal/external, was used total expected value. The reason for that is to enable comparison of internal and external impact on project, and their changes during the project. As the last step, in order to represent the "real" value of risk impact, weighted values $\mathrm{EV}$ and $\mathrm{S}$ have to be normalized with coefficient $n=\frac{\sum_{r} e v_{r}}{E R_{w}}=\frac{E R}{E R_{w}}$.

\section{Verification and validation of the method}

Verification is carried out in two phases. The first is the application of the method on the case study of large infrastructure project to demonstrate how the method is applied and used. The method was applied on railway reconstruction project. The total budget is 50 million Euros, and it is co-financed by Republic of Croatia and European Commission. Due to paper length limitation in this paper only results are shown and procedure described.

The first step of method is the determination of variables for each pre-defined project result, and the production of independent models for each variable. Project results taken into account are results for society and users, results for the delivering organisation, results for interested parties and project results and key project indicators. Each result has two lower levels of hierarchical structure. For the results of the lowest hierarchy level, units of measurement of consequences and measurement of impact are determined using two variables that can be modelled by quantitative methods - time and money (depending on the input data), where it is necessary to distinguish cost and benefit. In a given time 6 major risks were identified along with its components. The modelling process begins with the assessment of the impact of individual risks on each of the level III results. Due to the precisely defined method of the previously discussed qualitative risk analysis, each consequence may have an impact on more than one level III result. The total size of each level III score will be the result of the impact of all the consequences related thereto. To perform quantitative analysis it is necessary to determine the basis for 
Table 1. Results of risk based internal and external assessment

\begin{tabular}{|c|c|c|c|c|c|}
\hline & Indicators & Expected value (mil) & Risk efficiency & Slope & Relative risk efficiency \\
\hline \multirow{2}{*}{$\begin{array}{c}\text { Internal } \\
\text { assessment }\end{array}$} & Relative indicators & $-4.816 €$ & \multirow[t]{2}{*}{0.379} & -1.828 & \multirow[t]{2}{*}{0.367} \\
\hline & Normalized indicators & $-90.371 €$ & & -34.296 & \\
\hline \multirow{2}{*}{$\begin{array}{c}\text { External } \\
\text { assessment }\end{array}$} & Relative indicators & $-0.162 €$ & \multirow[t]{2}{*}{0.494} & -0.080 & \multirow[t]{2}{*}{0.016} \\
\hline & Normalized indicators & $-3.039 €$ & & -1.500 & \\
\hline \multirow{2}{*}{ TOTAL } & Relative indicators & $-4.978 €$ & \multirow[t]{2}{*}{0.873} & -1.908 & \multirow[t]{2}{*}{0.383} \\
\hline & Normalized indicators & $-93.410 €$ & & -35.796 & \\
\hline
\end{tabular}

risk analysis, i.e. the initial expected value for each result which is not a deterministic value and have to reflect the level of variability and ambiguity. Quantitative analysis of the data resulted in data in the form of probability distributions for each type III result expressed in money and time, and the result of sensitivity analysis for individual risks, which were the basis for qualitative internal and external project assessment.

AHP model was produced on the basis of expert estimates of the researcher based on conducted research and acquired knowledge based on purpose and importance of the project. The method assumes that for each project individual AHP model should be modelled which will include different internal stakeholder involved in project governance. This approach provides the necessary flexibility that is needed in order for the method to be applicable for different types of projects. Due to the long total duration of large projects and the turbulence to which they are exposed, it is hypothetically possible that the importance of individual sub-criteria might also change during the life cycle of the project. Therefore, this procedure needs to be carried out at the beginning of each project check.

To calculate the overall risk results score, synthesized weight in relation to the overall results is used. The result of project assessment is presented in Table 1. The results are showing the value of impact of internal and external influences on project. It is described with two sets of values:

1. Expected value provide us the fact how those influences can impact on future value of project results and

2. Related efficiency of risk and slope are telling us the degree of uncertainty arriving from those influences.

Therefore, result of this assessment is that internal influences are 30 times bigger than external influences. We can expect that internal influences can decrease total value of the project by 90,371 millions Euros and total range of influence is 34,296 million Euros. It is not unusual that expected value of risk impact of infrastructure projects can exceed overall project costs, because the risks were analysed against all success criteria which are used for determining the total value of the project. This verification confirms the research question that cumulative distribution (CDC) approach can be used to develop risk-based project assessment method assessment con- sidering project multi-criteria and complexity of causes that generate risks and project uncertainty. Risk model of components and characteristics enables taking into account complexity of causes that generates project risks and uncertainty and risk breakdown structure is used to consolidate information obtained from quantification of project uncertainty and risk components.

Since the aim of this research to develop a method for method for monitoring the progress of large infrastructure projects, which will address the large project characteristics (complexity, ambiguity, uncertainty) and to be accepted by experts and practitioner, the value of the method is validated using structured interview, based on case study simulations. The results are based on responses from 5 project managers and 5 cases simulations. Respondents have on average 10-15 years of experience in managing large infrastructure projects, mainly as project managers, but some of them were project sponsor and projects director as well. Respondents were asked to mark the method answering to 6 questions about importance of risk management in LIPs, importance of internal and external assessment and evaluation of LIPs, how appropriate are risks for internal and external assessment and evaluation of LIPs, how understandable, applicable and useful is the method (Table 2).

Answers were rated on Likert scale from 1-5 where 1 was very low and 5 very high. Respondents recognised risk management and internal and external assessment and evaluation as highly important for LIPs and that risks are highly appropriate for internal and external assessment and evaluation. The method was marked as highly useful, but due to complicated procedure the method received little lower rating. This is why respondents suggested that computer application would make the method highly understandable and applicable (Table 2).

The respondents were asked to state how this method would improve project management of LIPs. They stated that it would directly improve risk management improving visibility of risk in the project and results related with them. It would improve stakeholder management as well by improving communication between stakeholders and visibility of stakeholder's political influence and influence of public. It would also improve project monitoring and control focusing not only on time and money but to the other success criteria. 
Table 2. Results of the method verification

\begin{tabular}{l|c}
\hline \multicolumn{1}{c|}{ Question } & $\begin{array}{c}\text { Average } \\
\text { rating }\end{array}$ \\
\hline How important is risk management for LIPs? & 4.5 \\
\hline $\begin{array}{l}\text { How important is internal and external } \\
\text { assessment for LIPs? }\end{array}$ & 4 \\
\hline $\begin{array}{l}\text { How appropriate are risks for internal and } \\
\text { external assessment of LIPs? }\end{array}$ & 4 \\
\hline How understandable is the method? & 3.75 \\
\hline How applicable is the method? & 3.5 \\
\hline How useful is the method? & 4.25 \\
\hline
\end{tabular}

\section{Conclusions}

The paper presents the method for monitoring the progress of large infrastructure projects (LIPs) by monitoring internal and external influences on the project. The task of the project management of LIPs is to bring the project from initiation to delivery by minimizing influences external and internal towards the project. This is why is important to measure those influences in order to make right decisions at right time.

This method fills the gap in the area of assessment and progress evaluation of LIPs in front end. Moving from PxI risk impact modelling to CDC taking into account project uncertainties, it provides the tool for integration of uncertainty management in front end management.

During the project, influences can only be measured using quantification of risk sources, which reflect internal and external influences of the project. The impact of internal and external influences on project is described with two values:

1. Expected value provide us the fact how those influences can impact on future value of project results, and

2. Related risk efficiency together with slope are telling us the degree of uncertainty arriving from those influences.

Based on the concept illustrated on Figure 8. Interpretation of results these indicators can be used to evaluate progress of project development in two ways:

1. Is the value expected project value increasing or decreasing during the project development, and

2. Is project uncertainty decreasing or increasing during the project development.

Data are valuable for making risk-based project management strategy. This kind of analysis will give project manager insight into project health and give guidelines where the improvement has to be made considering all project results and its importance. Their internal/external ratio shows the quality of management performance. Specifically, a smaller proportion of internal assessment results in relation to external assessment results is an indication of problems in project management.
The experts recognised the value of this method stating the high value of usefulness of the method and providing answers how the method would improve the management of large infrastructure projects.

This method is especially valuable for infrastructure projects where project success exceeds the traditional time and cost criteria. It can be used for portraying the overall impact of risks and uncertainty on total project value. Therefore this method supports not only uncertainty management but value management concept as well.

This research considered risk and uncertainty impact modelling with linear cumulative curves, providing the tool for project managers to make the first step to move from "PxI" concept. Future research will examine how this method can be extended to the next level of risk modelling using non-linear cumulative s-curves.

\section{References}

Alfalla-Luque, R.; Burcar Dunović, I.; Gebbia, A.; Irimia-Diéguez, A. I.; Mikić, M.; Pedro, M. J. G.; SánchezCazorla, A.; de Abreu E Silva, J.; Spanng, K. 2015. Risk in front end of megaprojects. $2^{\text {nd }}$ ed. The RFE Working Group Report. University of Leeds.

Bu-Qammaz, A. S.; Dikmen, I.; Birgonul, M. T. 2009. Risk assessment of international construction projects using the analytic network process, Canadian Journal of Civil Engineering 36(7): 1170-1181.

http://dx.doi.org/10.1139/L09-061

Burcar Dunović, I.; Radujković, M.; Vukomanović, M. 2013. Developement and implementation of Risk register system for construction projects, Građevinar: Journal of Croatian Society of Civil Engineers 65(1): 23-35.

Burcar, I.; Radujković, M. 2009. Risk model for construction projects Risk register system, in Construction Facing Worldwide Chalenges - Joint 2008 CIB W065/W055 Commissions Symposium Proceedings, Dubrovnik, Faculty of Civil Engineering, University of Zagreb.

Cagno, E.; Caron, F.; Mancini, M. 2007. A multi-dimensional analysis of major risks in complex projects, Risk Management 9: 1-18.

http://dx.doi.org/10.1057/palgrave.rm.8250014

Ceric, A.; Marić, T. 2011. Determining priorities for managing risk on construction projects, Gradevinar 63(3): 265-271.

Chapman, C. 2006. Key points of contention in framing assumptions for risk and uncertainty management, International Journal of Project Management 24(4): 303-313. http://dx.doi.org/10.1016/j.ijproman.2006.01.006

Chapman, C.; Ward, S. 2004. Why risk efficiency is a key aspect of best practice projects, International Journal of Project Management 22(8): 619-632. http://dx.doi.org/10.1016/j.ijproman.2004.05.001

Chapman, C. B.; Ward, S. 2003. Project risk management: processes, techniques and insights. Wiley.

Charette, R. 1989. Software engineering risk analysis and management. McGraw Hill, USA.

Dikmen, I.; Birgonul, M. T.; Han, S. 2007. Using fuzzy risk assessment to rate cost overrun risk in international construction projects, International Journal of Project Management 25(5): 494-505. http://dx.doi.org/10.1016/j.ijproman.2006.12.002

Dorman, P. 2009. Markets and mortality: Economics, dangerous work, and the value of human life. Cambridge University Press. 
Dunovic, I. B. 2010. A study of project governance frameworks for large infrastructure projects with reflection on road transport projects, Organization, Technology \& Management in Construction: An International Journal 2(1): $145-155$.

Flyvbjerg, B.; Bank, W. 2005. Policy and planning for large infrastructure projects problems, causes, cures. Policy research working paper 3781. World Bank.

Hillson, D.; Simon, P. 2007. Practical project risk management: The atom methodology. Management Concepts, Incorporated.

Jaafari, A. 2001. Management of risks, uncertainties and opportunities on projects: time for a fundamental shift, International Journal of Project Management 19(2): 89-101. http://dx.doi.org/10.1016/S0263-7863(99)00047-2

Jannadi, O. A.; Almishari, S. 2003. Risk assessment in construction, Journal of Construction Engineering and Management 129(5): 492-500.

http://dx.doi.org/10.1061/(ASCE)0733-9364(2003)129:5(492)

Kim, S. G. 2010. Risk performance indexes and measurement systems for mega construction projects, Journal of Civil Engineering and Management 16(4): 586-594. http://dx.doi.org/10.3846/jcem.2010.65

Lazzerini, B.; Mkrtchyan, L. 2011. Analyzing risk impact factors using extended fuzzy cognitive maps, Systems Journal IEEE 5(2): 288-297. http://dx.doi.org/10.1109/JSYST.2011.2134730

Max, W.; Rice, D. P.; Sung, H.-Y.; Michel, M. 2004. Valuing human life: Estimating the present value of lifetime earnings, 2000. UC San Francisco, Center for Tobacco Control Research and Education.

Miller, R.; Hobbs, B. 2005. Governance regimes for large complex projects, Project Management Journal 36(2): 42-50.

Miller, R.; Lessard, D. R. 2000. The strategic management of large engineering projects: shaping institutions, risks and governance. Massachusetts: Massachusetts Institute of Technology.

Patterson, F. D.; Neailey, K. 2002. A Risk Register Database System to aid the management of project risk, International Journal of Project Management 20(5): 365-374. http://dx.doi.org/10.1016/S0263-7863(01)00040-0

Pender, S. 2001. Managing incomplete knowledge: why risk management is not sufficient, International Journal of Project Management 19(2): 79-87. http://dx.doi.org/10.1016/S0263-7863(99)00052-6
Radujković, M.; Burcar, I. 2005. Risk breakdown structure for construction projects, in CTIC-III, The Third International Conference on Construction in the $21^{\text {st }}$ Century, 2005, Atena, Greece.

Radujković, M.; Vukomanović, M.; Burcar Dunović, I. 2010. Application of key performance indicators in South-Eastern European construction, Journal of Civil Engineering and Management 16(4): 521-530. http://dx.doi.org/10.3846/jcem.2010.58

Samset, K.; Volden, G. H. 2014. Front end governance of major public projects - lessons with Norwegian quality assurance scheme, International Journal of Architecture, Engineering and Construction 3(2): 110-119.

Lu, S.-T.; Lin, C.-W.; Ko, P.-H. 2007. Application of Analytic Network Process (ANP) in assessing construction risk of urban bridge project, in Second International Conference on Innovative Computing, Information and Control (ICICIC 07), 5-7 September 2007, Kumamoto. http://dx.doi.org/10.1109/ICICIC.2007.172

Tah, J. H. M.; Carr, V. 2001. Knowledge-base approach to construction project risk management, Journal of Computing in Civil Engineering 15(3): 170-177.

http://dx.doi.org/10.1061/(ASCE)0887-3801(2001)15:3(170)

Taroun, A. 2014. Towards a better modelling and assessment of construction risk: Insights from a literature review, International Journal of Project Management 32(1): 101-115. http://dx.doi.org/10.1016/j.ijproman.2013.03.004

Taroun, A.; Yang, J. B.; Lowe, D. 2011. Construction risk modelling and assessment: Insights from a literature review, The Built \& Human Environment Review 4(1): 87-97.

Williams, T. M. 1996. The two-dimensionality of project risk, International Journal of Project Management 14(3): 185186. http://dx.doi.org/10.1016/0263-7863(96)00030-0

Zavadskas, E. K.; Turskis, Z.; Tamošaitiene, J. 2010. Risk assessment of construction projects, Journal of Civil Engineering and Management 16(1): 33-46. http://dx.doi.org/10.3846/jcem.2010.03

Zhang, H. 2007. A redefinition of the project risk process: using vulnerability to open up the event-consequence link, International Journal of Project Management 25(7): 694-701. http://dx.doi.org/10.1016/j.ijproman.2007.02.004

Ivana BURCAR DUNOVIĆ. An Assistant Professor at the University of Zagreb, Croatia. She was a researcher on several research projects on risk management in construction projects, especially in large infrastructure projects. Her recent research activities are related with her involvement in COST Action Megaproject: The Effective Design and Delivery of Megaprojects in the European Union as Committee Member, as a member of Working group "Managing External Stakeholders" and Leader of Working group "Risk in Front End". She is a member of CIB, IPMA, and NETLIPSE where she is member of Scientific Committee. She is trained IPMA Excellence Award Assessor and Infrastructure Project Assessments Tool Assessor. Her research interests are risk management, key performance indicators, project governance, large project assessment and evaluation, management control systems, scheduling techniques, project management processes and IT in construction.

Mladen RADUJKOVIĆ. A Full Tenured Professor at the University of Zagreb, Croatia. He is editor-in-chief of the Organization, Technology and Management in Construction: An International Journal, president of the Croatian Association for Project Management and the president of IPMA. He leads the research project "Risk and change management in the project oriented construction business". His research interests are project management, risk management, management control systems, scheduling techniques, change management and operational research.

Mladen VUKOMANOVIĆ. An Assistant Professor at the University of Zagreb, Croatia. He leads a research project "Business excellence in the construction industry in Croatia". He is the managing editor of Organization, Technology and Management in Construction: An International Journal. He is a member of CIB, IPMA, Performance Measurement Association. His research interests are performance management, key performance indicators, benchmarking, TQM, strategic management in construction, project management processes and IT in construction. 